\title{
COVID-19 Vaccination and Menstrual Issues - A Survey
}

\author{
Sheela.J \\ HOD-OBG Nursing, R V College of Nursing \& Ph.D. Scholar, Shri JJTU University, Rajasthan
}

\begin{abstract}
The present study was aimed to assess the menstrual issues post COVID 19 vaccination.

The objectives of the study were to assess the menstrual issues post COVID 19 vaccination \& to find the association between menstrual issues and socio demographic variables. The study was conducted among 100 female participants who were vaccinated against COVID 19, using purposive sampling method.
\end{abstract}

The present study showed that $88 \%$ had taken Covishield and $12 \%$ had taken Covaxin. Majority that is $68 \%$ of the female participants belonged to the age group of $18-26$ years, $63 \%$ were Hindus and $65 \%$ belonged to nuclear family. In terms of the educational status $55 \%$ were graduates and $49 \%$ were studying. Majority that is $67 \%$ had their first menstrual period at the age of $13-15$ years and $91 \%$ had no menstrual problem before Covid 19 vaccination. Distribution of 88 female participants according to Covishield vaccine and the menstrual issues revealed that $14 \%$ had missed periods, $10 \%$ had bleeding or spotting in between periods, $13 \%$ had menstrual bleeding lasting long, $58 \%$ had menstrual cramps, $18 \%$ had heavy periods, $24 \%$ had breast tenderness, 39\% had abdominal bloating, $27 \%$ had extreme tiredness, $11 \%$ had constipation and $47 \%$ had mood swings.

Distribution of 12 female participants according to Covaxin vaccine and the menstrual issues revealed that $33 \%$ had missed periods, $25 \%$ had bleeding or spotting in between periods, $08 \%$ had menstrual bleeding lasting long, 50\% had menstrual cramps, $17 \%$ had heavy periods, $33 \%$ had breast tenderness, $33 \%$ had abdominal bloating, $67 \%$ had extreme tiredness, $25 \%$ had constipation and $58 \%$ had mood swings.

Distribution of female participants aged $<20$ years who were vaccinated with Covishield/ Covaxin revealed that none of the participants in this age group reported any menstrual issues except one person who had extreme tiredness after Covaxin. Chi-Square test or proportion test no possible for both Covishield and Covaxin in age group $<20$ as observed frequencies do not match requirements of the test.

Distribution of female participants aged 20 -29 years who were vaccinated with Covishield/ Covaxin revealed that for Covishield the proportion test for menstrual cramps revealed $\mathrm{Z}=0.426$ (not significant, ' $p$ '>0.05), abdominal bloating $Z=7.249$ (significant, ' $p$ ' $<0.01$ ) and mood swing $Z=2.558$ (significant, 'p' $<0.01$ ) For Covaxin Chi square or proportion test not possible in age group 20 - 29 years as observed frequencies do not match requirements of the test.

Distribution of female participants aged 30-39 years who were vaccinated with Covishield/ Covaxin revealed that for Covishield the proportion test for breast tenderness revealed $Z=0.343$ (not significant, 'p'>0.05). Chi square test \& proportion test for missed bleeding, periods lasting long, and cramps is not possible as the observed frequencies do not match requirements of the test. For Covaxin Chi square or proportion test not possible in age group 30 39 years as observed frequencies do not match requirements of the test.

Distribution of female participants aged 40-49 years who were vaccinated with Covishield, majority had menstrual issues and those who were vaccinated with Covaxin 50\% had no menstrual issues. Chi -Square test or proportion test no possible for both Covishield and Covaxin in age group 40-49 years as observed frequencies do not match requirements of the test.

Only one female participant aged 50 years and above was vaccinated with Covishield and she had menstrual issues before vaccination 
too. Therefore statistical analysis possible in this case.

A quantitative non- experimental survey approach was chosen for the study. Menstrual issues post COVID 19 vaccination was assessed using a structured questionnaire.

Key words: COVID 19, vaccination, Covishield, Covaxin, menstrual issues.

\section{INTRODUCTION}

COVID-19 pandemic has become a global issue calling for emergency interventions. To fight this deadly disease, it is necessary to prepare the immune system \& train it to develop the body's natural defences, in the form of vaccines, which destroys the viruses when one is exposed to it and thereby preventing the illness. Vaccines can play a vital role in changing the foreseeable future.

WHO states that as of 18 February 2021, at least seven different vaccines across three platforms have been rolled out in countries. At the same time, more than 200 additional vaccine candidates are in development, of which more than 60 are in clinical development.

In India the Central Drug Standards Control Organization (CDSCO) has granted emergency use authorization to two vaccines namely Covishield and Covaxin. These vaccines were provided on priority to the health care and frontline workers, which was later extended to 45 and above and now 18 and above.

Although COVID-19 has been proved to be safe, some individuals could develop common side effects like mild fever, pain, etc. Not much is known, but reports of COVID-19 vaccines causing irregular bleeding have been anecdotal. And it is hard to draw any direct links to the vaccine since changes could be the result of other factors including stress, diet, and exercise habits.

Therefore this study is focused to identify the impact of both the COVID-19 vaccines, Covishield and Covaxin on menstrual health leading to menstrual issues such as missed period, bleeding or spotting between periods, menstrual bleeding lasting long, menstrual cramps, heavy periods, breast tenderness, abdominal bloating, extreme tiredness, constipation, mood swings, etc.

\section{MATERIALS \& METHODS}

Survey approach is used to identify the impact of both the COVID-19 vaccines, Covishield and Covaxin on menstrual health. The study is conducted on female samples who had taken COVID-19 vaccination and who were in the reproductive age. Purposive sampling technique was found to be appropriate to select the female samples. The sample size for this study was 100 female participants who fulfilled the inclusion criteria.

The tool used for this study was a Google form which consisted of questions on Socio demographic data of the female participant' $s$ age, religion, type of family, educational status, occupation, age at first menstrual period, menstrual problems before COVID-19 vaccination and the type of vaccination taken. Structured questionnaire consisting 10 questions was used to assess any menstrual issues after the vaccination. The informed consent was taken from all the female samples who agreed to participate in the study. Data analysis was done on the basis of descriptive and inferential statistics.

\section{RESULTS}

The results of the study are presented under following headings.

Section1: Demographic data of female participants.

Section 2: Type of vaccine taken by the female participants.

Section 3: Impact of both Covishield and Covaxin on menstrual health.

\section{Section 1: Demographic data of female participants.}

Table 1: Distribution of female participants according to age $\mathbf{N}=\mathbf{1 0 0}$

\begin{tabular}{|c|c|c|}
\hline Age & Frequency & Percentage \\
\hline $18-26$ years & 68 & 68 \\
\hline $27-35$ years & 14 & 14 \\
\hline $36-44$ years & 12 & 12 \\
\hline $45-53$ years & 06 & 06 \\
\hline
\end{tabular}


Table 1 shows that $68 \%$ were in the age group of $18-26,14 \%$ were in the age group of $27-35$ years, $12 \%$ were in the age group of 36-44 years and $06 \%$ were in the age group of 45-53 years

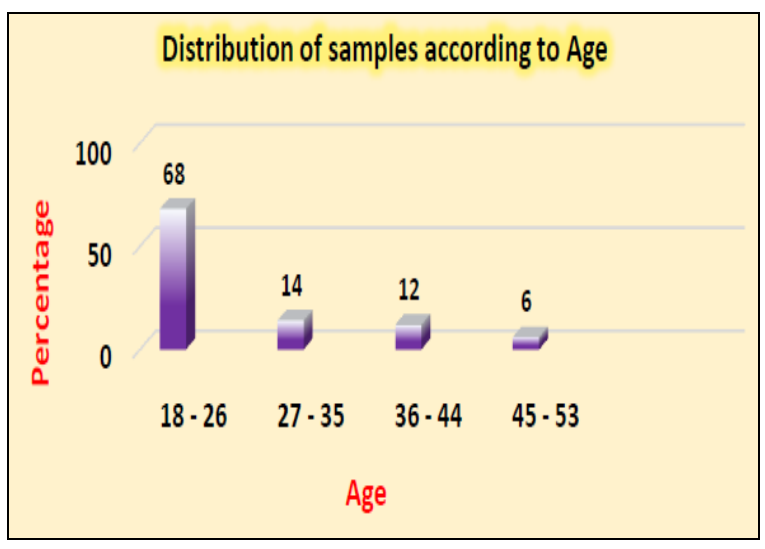

Table 2: Distribution of subjects according to religion $\mathrm{N}=100$

\begin{tabular}{|c|c|c|}
\hline Religion & Frequency & Percentage \\
\hline Hindu & 63 & $63 \%$ \\
\hline Muslim & 17 & $17 \%$ \\
\hline Christian & 20 & $20 \%$ \\
\hline Others & 0 & 0 \\
\hline
\end{tabular}

Table 2 shows that $63 \%$ of female subjects were in Hindu, $17 \%$ were Muslim and $20 \%$ were Christians.

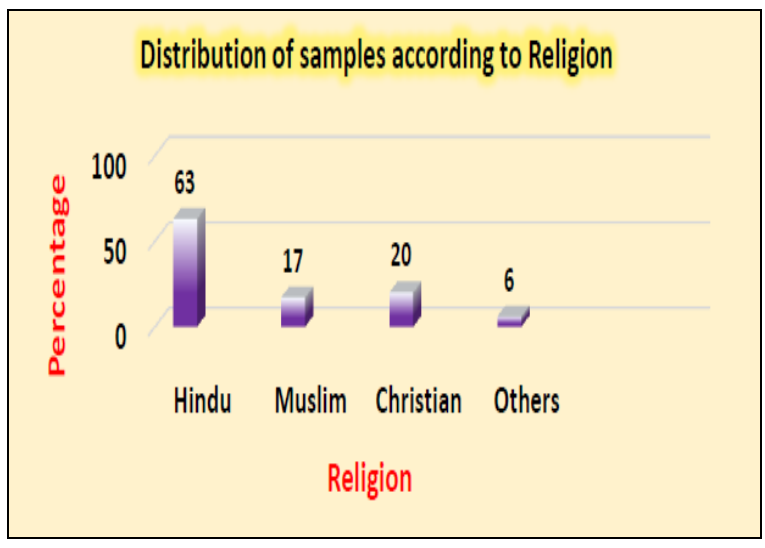

Table 3: Distribution of subjects according to type of family $\mathbf{N}=\mathbf{1 0 0}$

\begin{tabular}{|c|c|c|}
\hline Type of family & Frequency & Percentage \\
\hline Nuclear family & 65 & 65 \\
\hline Joint family & 31 & 31 \\
\hline Extended & 04 & 04 \\
\hline
\end{tabular}

Table 3 shows that $65 \%$ of female participants belonged to nuclear $31 \%$ belonged to joint family and $04 \%$ belonged to extended family.

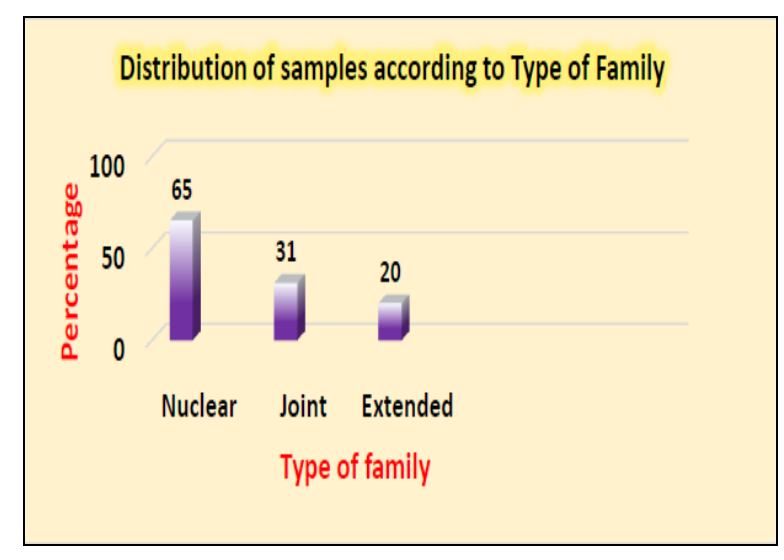

Table 4: Distribution of female subjects according to educational status $\quad \mathbf{N}=\mathbf{1 0 0}$

\begin{tabular}{|l|c|c|}
\hline \multicolumn{1}{|c|}{ Educational status } & Frequency & Percentage \\
\hline No formal education & 03 & 03 \\
\hline Primary Education & 01 & 01 \\
\hline Secondary Education & 02 & 02 \\
\hline Pre University & 39 & 39 \\
\hline Graduation & 55 & 55 \\
\hline
\end{tabular}

Table 4 shows that $03 \%$ of female participants had no formal education, $01 \%$ had primary education, $02 \%$ had secondary education, 39\% had Pre university education and $55 \%$ had a degree.

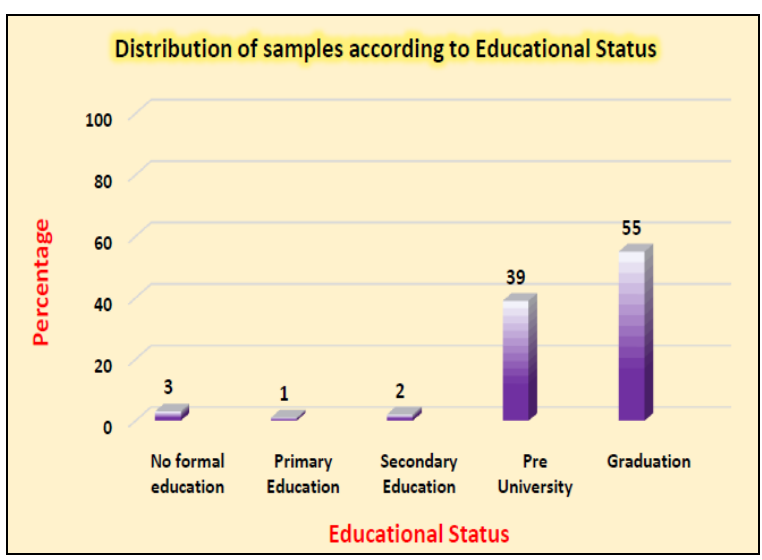

Table 5: Distribution of female subjects according to occupational status $\quad \mathbf{N}=\mathbf{1 0 0}$

\begin{tabular}{|l|c|c|}
\hline Occupational Status & Frequency & Percentage \\
\hline Home maker & 07 & 07 \\
\hline Government employee & 05 & 05 \\
\hline Private employee & 39 & 39 \\
\hline Self employed & 00 & 00 \\
\hline Studying & 49 & 49 \\
\hline
\end{tabular}

Table 5 shows that $07 \%$ of female participants were homemakers, $05 \%$ were government employees, $39 \%$ were private employees, none were self-employed and $49 \%$ were studying. 


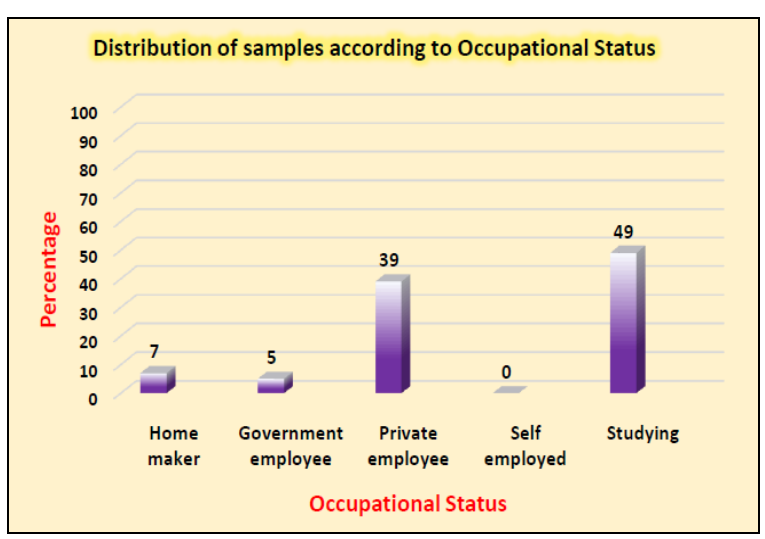

Table 6: Distribution of female subjects according to age at first menstrual period $\mathrm{N}=100$

\begin{tabular}{|c|c|c|}
\hline Age at first menstrual period & Frequency & Percentage \\
\hline $10-12$ & 24 & 24 \\
\hline $13-15$ & 67 & 67 \\
\hline $16-18$ & 09 & 09 \\
\hline
\end{tabular}

Table 6 shows that $24 \%$ of female participants had the first menstrual period at $10-12$ years, $67 \%$ at $13-15$ years and $09 \%$ at 16-18 years.

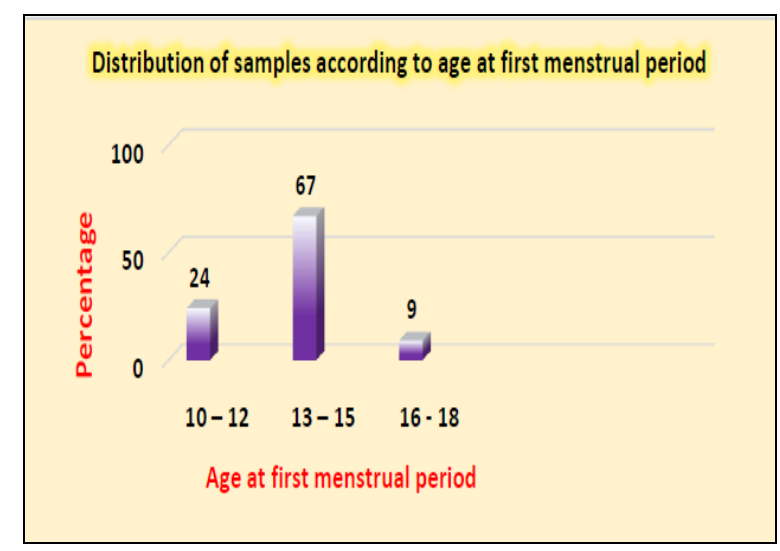

Table 7: Distribution of female subjects according to any menstrual problem before COVID-19 vaccination $N=100$

\begin{tabular}{|c|c|c|}
\hline $\begin{array}{c}\text { Menstrual problem before } \\
\text { COVID - 19 vaccination }\end{array}$ & Frequency & Percentage \\
\hline Yes & 09 & 09 \\
\hline No & 91 & 91 \\
\hline
\end{tabular}

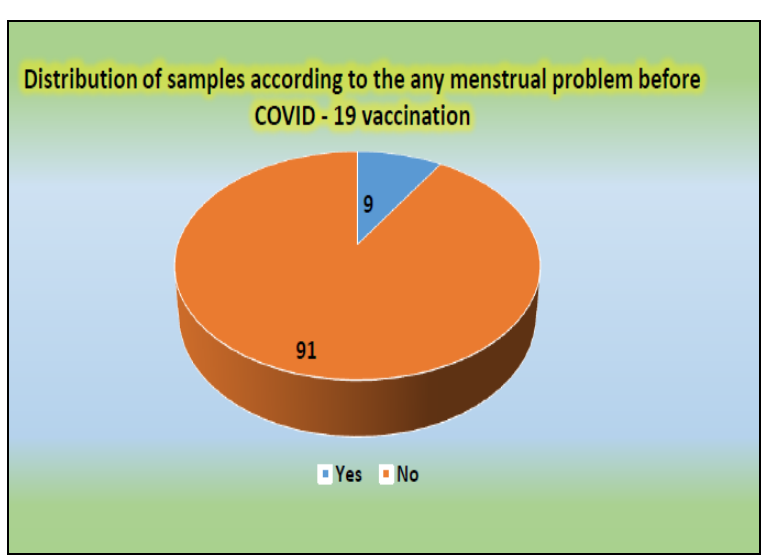

Table 7 shows that $09 \%$ of female participants had menstrual problem before COVID-19 vaccination and $91 \%$ had no menstrual problem.

\section{Section 2: Type of vaccine taken by female participants}

Table 8: Distribution of female participants according to the type of vaccine taken $\mathrm{N}=\mathbf{1 0 0}$

\begin{tabular}{|l|c|c|}
\hline Type of the Vaccine & Frequency & Percentage \\
\hline Covishield & 88 & 88 \\
\hline Covaxin & 12 & 12 \\
\hline
\end{tabular}

Table 8 shows that $88 \%$ of female participants had taken Covishield and $12 \%$ had taken Covaxin

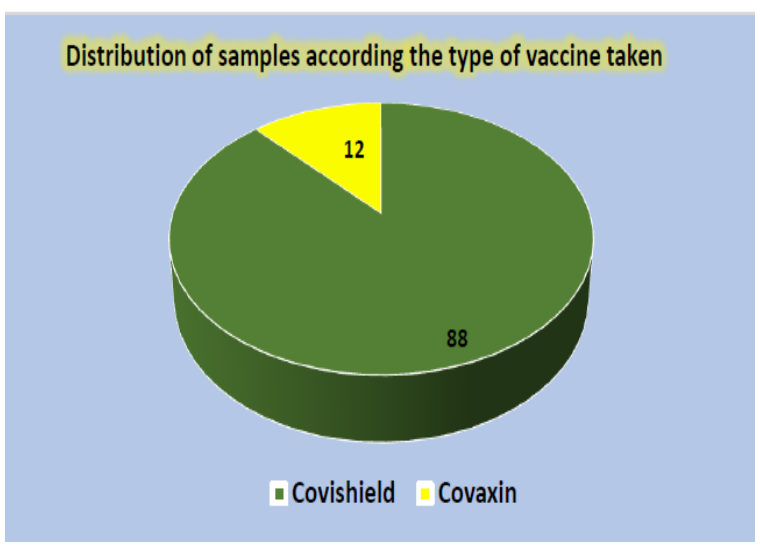

\section{Section 3: Impact of both Covishield and Covaxin on menstrual health}

Table 9: Distribution of female participants according to

Covishield vaccine and the menstrual issues $\quad \mathbf{N}=88$

\begin{tabular}{|} 
Covishield vaccine and the menstrual issues \\
\begin{tabular}{|l|c|c|c|c|}
\hline \multicolumn{1}{|c|}{ Menstrual issues } & \multicolumn{4}{|c|}{ Covishield } \\
\cline { 2 - 5 } & Yes & $\%$ & No & $\%$ \\
\hline 1.Missed Period & 12 & 14 & 76 & 86 \\
\hline $\begin{array}{l}\text { 2. Bleeding or spotting in between } \\
\text { periods }\end{array}$ & 09 & 10 & 79 & 90 \\
\hline 3. Menstrual bleeding lasting long & 11 & 13 & 77 & 87 \\
\hline 4. Menstrual cramps & 51 & 58 & 37 & 42 \\
\hline 5. Heavy periods & 16 & 18 & 72 & 82 \\
\hline 6. Breast tenderness & 21 & 24 & 67 & 76 \\
\hline 7. Abdominal bloating & 34 & 39 & 54 & 61 \\
\hline 8. Extreme tiredness & 24 & 27 & 64 & 73 \\
\hline 9. Constipation & 10 & 11 & 78 & 89 \\
\hline 10. Mood swing & 41 & 47 & 47 & 53 \\
\hline
\end{tabular}
\end{tabular}

Table 9 shows the distribution of female participants according to Covishield vaccine and the menstrual issues it was found that $14 \%$ had missed periods, $10 \%$ had bleeding or spotting in between periods, $13 \%$ had menstrual bleeding lasting long, $58 \%$ had menstrual cramps, $18 \%$ had heavy 
periods, 24\% had breast tenderness, 39\% had abdominal bloating, $27 \%$ had extreme tiredness, $11 \%$ had constipation and $47 \%$ had mood swings.

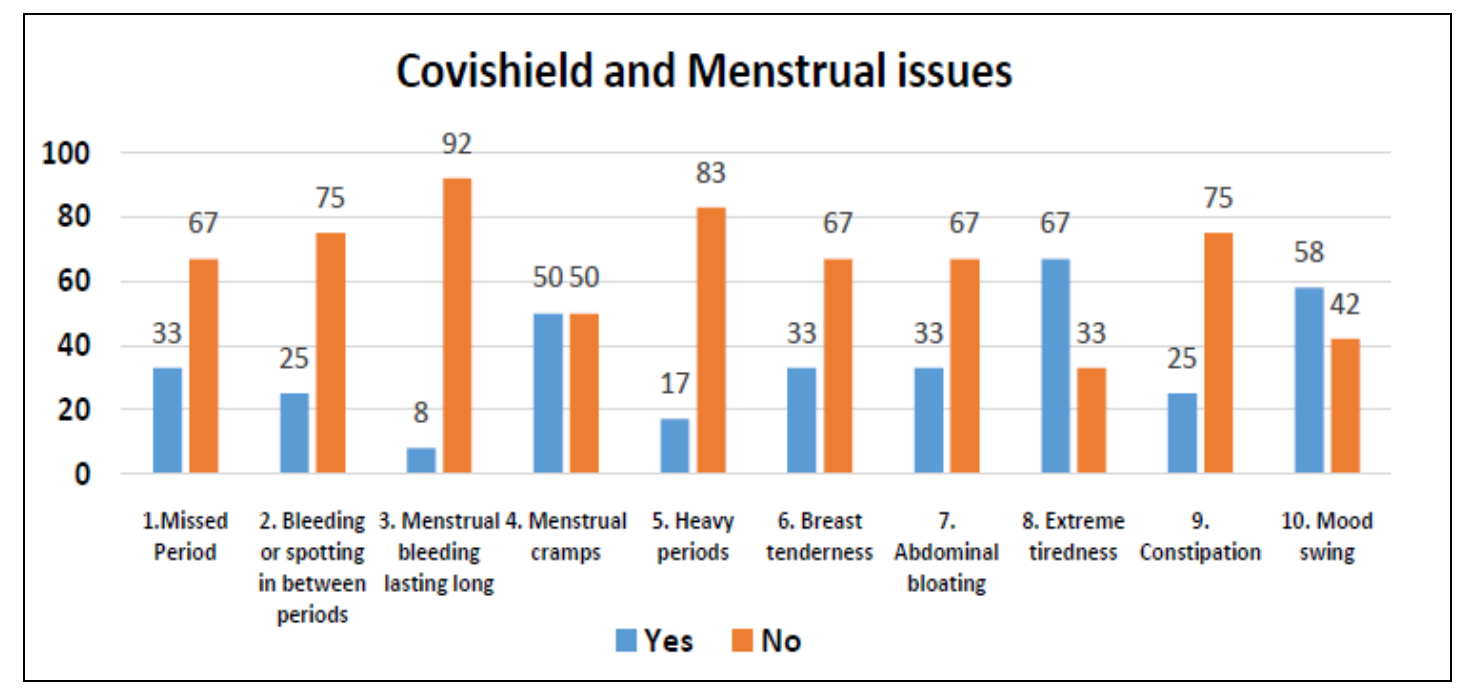

Table 10: Distribution of female participants according to Covaxin vaccine and the menstrual issues $\mathrm{N}=12$

\begin{tabular}{|l|c|c|c|c|}
\hline \multirow{2}{*}{ Menstrual issues } & \multicolumn{4}{|c|}{ Covaxin } \\
\cline { 2 - 5 } & Yes & $\%$ & No & $\%$ \\
\hline 1.Missed Period & 04 & 33 & 08 & 67 \\
\hline 2. Bleeding or spotting in between periods & 03 & 25 & 09 & 75 \\
\hline 3. Menstrual bleeding lasting long & 01 & 08 & 11 & 92 \\
\hline 4. Menstrual cramps & 06 & 50 & 06 & 50 \\
\hline 5. Heavy periods & 02 & 17 & 10 & 83 \\
\hline 6. Breast tenderness & 04 & 33 & 08 & 67 \\
\hline 7. Abdominal bloating & 04 & 33 & 08 & 67 \\
\hline 8. Extreme tiredness & 08 & 67 & 04 & 33 \\
\hline 9. Constipation & 03 & 25 & 09 & 75 \\
\hline 10. Mood swing & 07 & 58 & 05 & 42 \\
\hline
\end{tabular}

Table 10 shows the distribution of female participants according to Covaxin vaccine and the menstrual issues and it was found that $33 \%$ had missed periods, $25 \%$ had bleeding or spotting in between periods, 08\% had menstrual bleeding lasting long,
$50 \%$ had menstrual cramps, $17 \%$ had heavy periods, 33\% had breast tenderness, 33\% had abdominal bloating, $67 \%$ had extreme tiredness, $25 \%$ had constipation and $58 \%$ had mood swings.

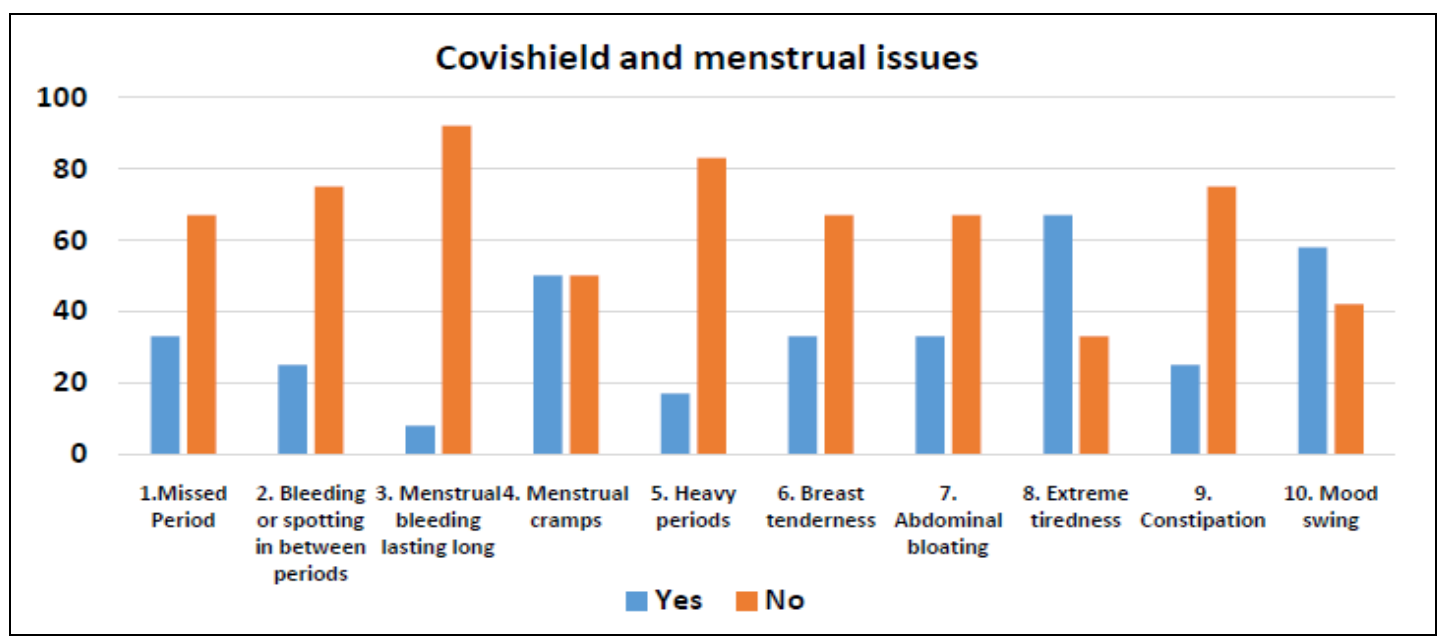


Table 11 shows distribution of female participants aged $<20$ years who were vaccinated with Covishield/Covaxin and it was found the none of the participants in this age group reported any menstrual issues except one person who had extreme tiredness after Covaxin. Chi - Square test or proportion test no possible for both Covishield and Covaxin in age group $<20$ as observed frequencies do not match requirements of the test.

Table 11: Distribution of female participants aged <20 years who were vaccinated with Covishield/Covaxin and the menstrual issues

\begin{tabular}{|l|c|c|c|c|c|c|c|c|}
\hline \multicolumn{1}{|c|}{ Menstrual issues } & \multicolumn{3}{c|}{ Covishield $\mathbf{N}=\mathbf{1 6})$} & \multicolumn{4}{c|}{ Covaxin $(\mathbf{N}=\mathbf{0 5})$} \\
\cline { 2 - 9 } & Yes & $\mathbf{\%}$ & $\mathbf{N o}$ & $\mathbf{\%}$ & Yes & $\mathbf{\%}$ & $\mathbf{N o}$ & $\mathbf{\%}$ \\
\hline 1.Missed Period & 00 & 00 & 16 & 100 & 00 & 00 & 05 & 100 \\
\hline 2. Bleeding or spotting in between periods & 00 & 00 & 16 & 100 & 00 & 00 & 05 & 100 \\
\hline 3. Menstrual bleeding lasting long & 00 & 00 & 16 & 100 & 00 & 00 & 05 & 100 \\
\hline 4. Menstrual cramps & 00 & 00 & 16 & 100 & 00 & 00 & 05 & 100 \\
\hline 5. Heavy periods & 00 & 00 & 16 & 100 & 00 & 00 & 05 & 100 \\
\hline 6. Breast tenderness & 00 & 00 & 16 & 100 & 00 & 00 & 05 & 100 \\
\hline 7. Abdominal bloating & 00 & 00 & 16 & 100 & 00 & 00 & 05 & 100 \\
\hline 8. Extreme tiredness & 00 & 00 & 16 & 100 & 01 & 20 & 04 & 80 \\
\hline 9. Constipation & 00 & 00 & 16 & 100 & 00 & 00 & 05 & 100 \\
\hline 10. Mood swing & 00 & 00 & 16 & 100 & 00 & 00 & 05 & 100 \\
\hline
\end{tabular}

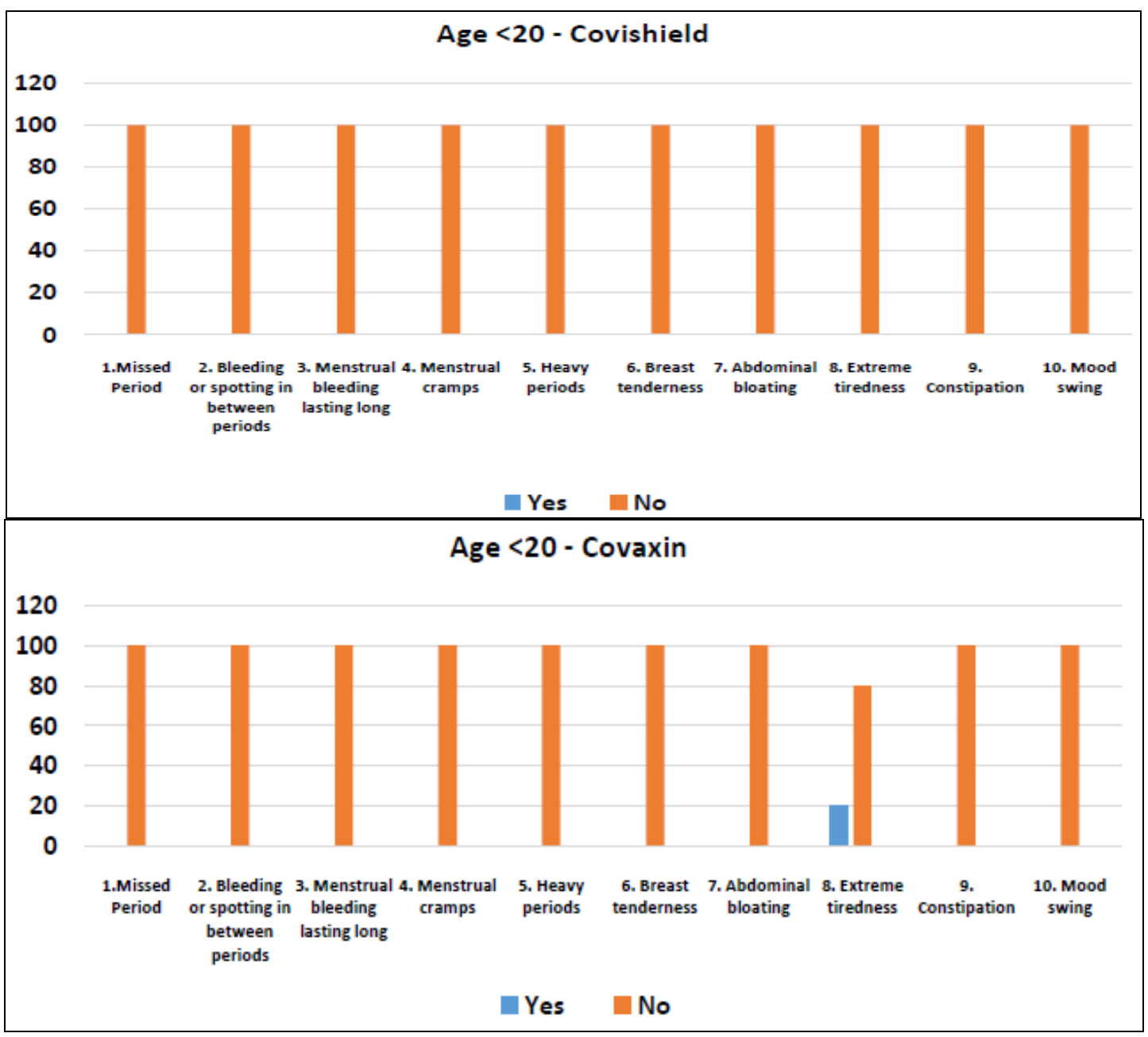

Table 12 shows distribution of female participants aged 20 -29 years who were vaccinated with Covishield/Covaxin and it was found that for Covishield the proportion test for menstrual cramps revealed $\mathrm{Z}=0.426 \quad$ (not significant, 'p'
$>0.05), \quad$ abdominal bloating $\mathrm{Z}=7.249$ (significant, 'p' $<0.01$ ) and $\operatorname{mood}$ swing $\mathrm{Z}=$ 2.558 (significant, 'p' $<0.01$ )

For Covaxin Chi square or proportion test not possible in age group 20- 
29 years as observed frequencies do not match requirements of the test.

Table 12: Distribution of female participants aged 20-29 years who were vaccinated with Covishield/Covaxin and the menstrual issues

\begin{tabular}{|l|c|c|c|c|c|c|c|c|}
\hline \multirow{2}{*}{ Menstrual issues } & \multicolumn{3}{|c|}{ Covishield (N $\mathbf{4 4})$} & \multicolumn{4}{c|}{ Covaxin (N= 04) } \\
\cline { 2 - 10 } & Yes & $\mathbf{\%}$ & No & $\mathbf{\%}$ & Yes & $\mathbf{\%}$ & No & $\%$ \\
\hline 1.Missed Period & 00 & 00 & 44 & 100 & 01 & 25 & 03 & 75 \\
\hline 2. Bleeding or spotting in between periods & 00 & 00 & 44 & 100 & 00 & 00 & 04 & 100 \\
\hline 3. Menstrual bleeding lasting long & 00 & 00 & 44 & 100 & 00 & 00 & 04 & 100 \\
\hline 4. Menstrual cramps & 21 & 48 & 23 & 52 & 03 & 75 & 01 & 25 \\
\hline 5. Heavy periods & 00 & 00 & 44 & 100 & 00 & 00 & 04 & 100 \\
\hline 6. Breast tenderness & 00 & 00 & 44 & 100 & 01 & 25 & 03 & 75 \\
\hline 7. Abdominal bloating & 05 & 11 & 39 & 89 & 01 & 25 & 03 & 75 \\
\hline 8. Extreme tiredness & 00 & 00 & 44 & 100 & 00 & 00 & 04 & 100 \\
\hline 9. Constipation & 00 & 00 & 44 & 100 & 00 & 00 & 04 & 100 \\
\hline 10. Mood swing & 16 & 36 & 28 & 64 & 00 & 00 & 04 & 100 \\
\hline
\end{tabular}

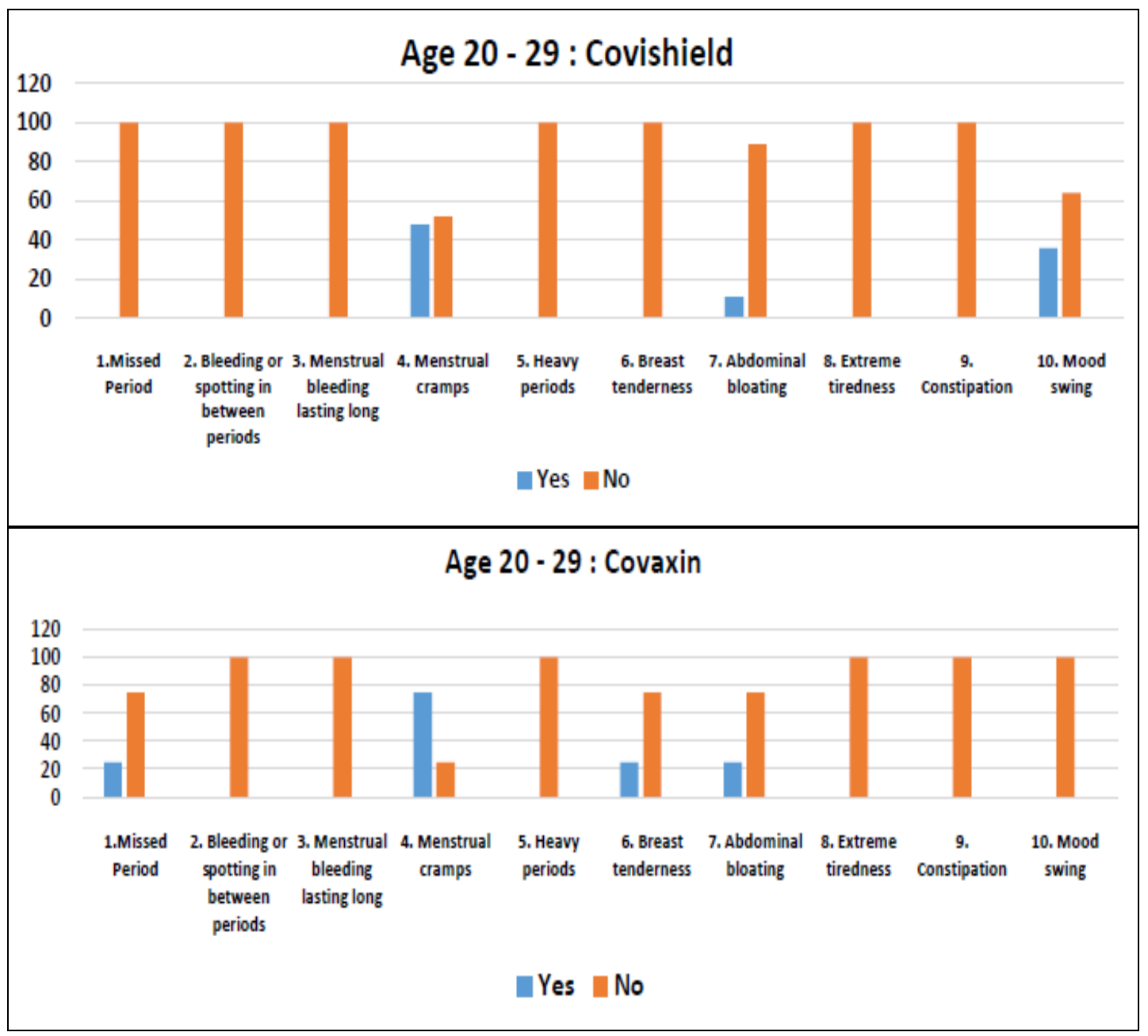

Table 13: Distribution of female participants aged 30-39 years who were vaccinated with Covishield/Covaxin and the menstrual issues.

\begin{tabular}{|l|c|c|c|c|c|c|c|c|}
\hline \multirow{2}{*}{ Menstrual issues } & \multicolumn{4}{|c|}{ Covishield $(\mathbf{N}=\mathbf{1 7})$} & \multicolumn{4}{c|}{ Covaxin $(\mathbf{N}=\mathbf{0 1})$} \\
\cline { 2 - 11 } & Yes & $\mathbf{\%}$ & No & \% & Yes & \% & No & $\%$ \\
\hline 1.Missed Period & 02 & 12 & 15 & 88 & 01 & 100 & 00 & 00 \\
\hline 2. Bleeding or spotting in between periods & 00 & 00 & 17 & 100 & 01 & 100 & 00 & 00 \\
\hline 3. Menstrual bleeding lasting long & 02 & 12 & 15 & 88 & 00 & 00 & 01 & 100 \\
\hline 4. Menstrual cramps & 17 & 100 & 00 & 00 & 01 & 100 & 00 & 00 \\
\hline 5. Heavy periods & 05 & 29 & 12 & 71 & 00 & 00 & 01 & 100 \\
\hline 6. Breast tenderness & 08 & 47 & 09 & 53 & 01 & 100 & 00 & 00 \\
\hline 7. Abdominal bloating & 17 & 100 & 00 & 00 & 01 & 100 & 00 & 00 \\
\hline 8. Extreme tiredness & 16 & 94 & 01 & 06 & 01 & 100 & 00 & 00 \\
\hline 9. Constipation & 00 & 00 & 17 & 100 & 01 & 100 & 00 & 00 \\
\hline 10. Mood swing & 17 & 100 & 00 & 00 & 01 & 100 & 00 & 00 \\
\hline
\end{tabular}


Table 13 shows distribution of female participants aged 30-39 years who were vaccinated with Covishield/Covaxin and it was found for Covishield the proportion test for breast tenderness revealed $\mathrm{Z}=0.343$ (not significant, ' $\mathrm{p}$ ' $>0.05)$. Chi square test $\&$ proportion test for missed bleeding, periods lasting long, and cramps is not possible as the observed frequencies do not match requirements of the test.

For Covaxin Chi square or proportion test not possible in age group 3039 years as observed frequencies do not match requirements of the test.

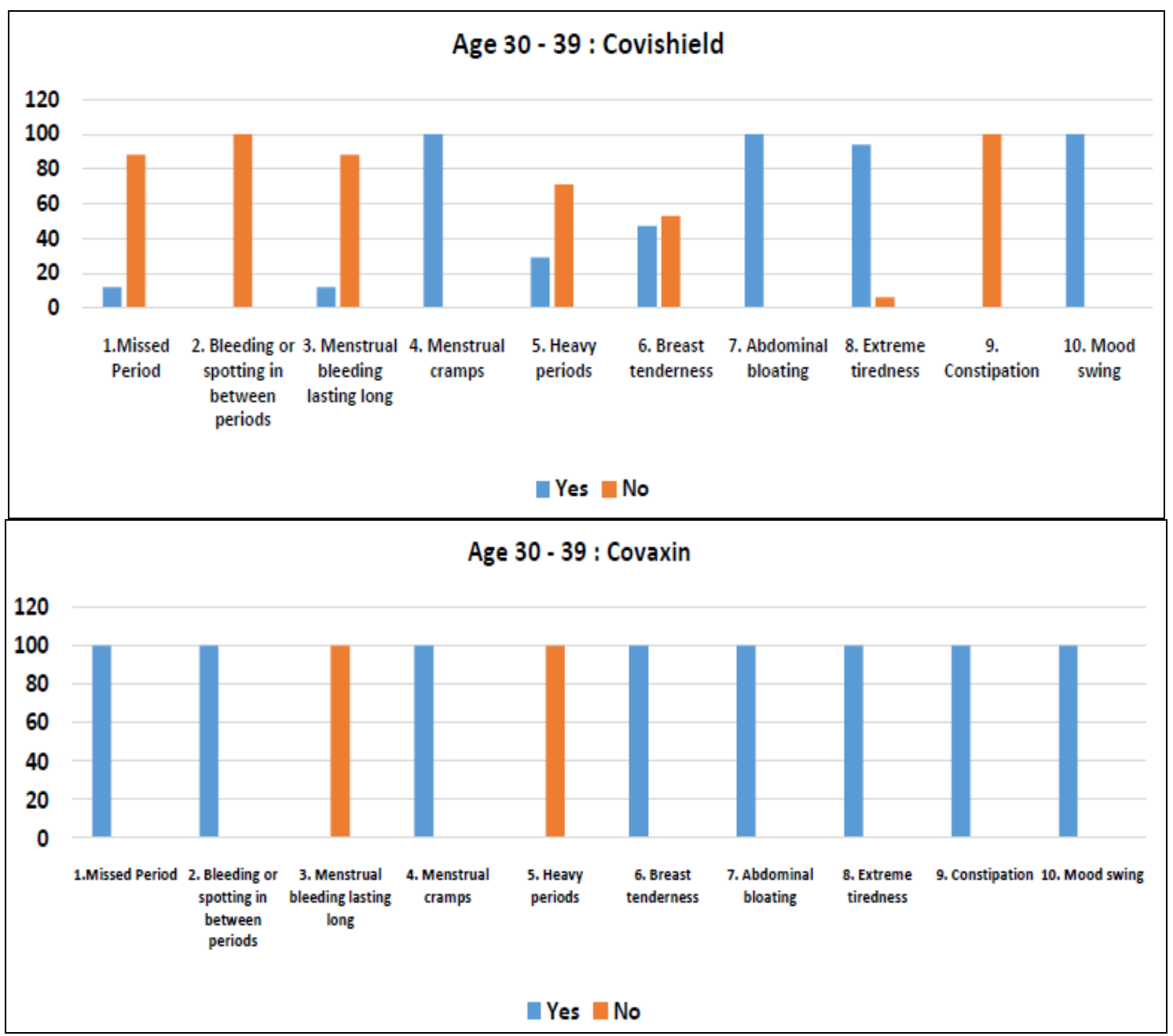

Table 14: Distribution of female participants aged $40-49$ years who were vaccinated with Covishield/Covaxin and the menstrual issues.

\begin{tabular}{|l|c|c|c|c|c|c|c|c|}
\hline \multirow{2}{*}{ Menstrual issues } & \multicolumn{3}{|c|}{ Covishield $(\mathbf{N}=\mathbf{1 0})$} & \multicolumn{4}{c|}{ Covaxin $(\mathbf{N}=\mathbf{0 2})$} \\
\cline { 2 - 9 } & Yes & $\mathbf{\%}$ & No & $\mathbf{\%}$ & Yes & $\mathbf{\%}$ & No & $\%$ \\
\hline 1.Missed Period & 10 & 100 & 00 & 00 & 02 & 100 & 00 & 00 \\
\hline 2. Bleeding or spotting in between periods & 09 & 90 & 01 & 10 & 02 & 100 & 00 & 00 \\
\hline 3. Menstrual bleeding lasting long & 10 & 100 & 00 & 00 & 01 & 50 & 01 & 50 \\
\hline 4. Menstrual cramps & 10 & 100 & 00 & 00 & 02 & 100 & 00 & 00 \\
\hline 5. Heavy periods & 10 & 100 & 00 & 00 & 02 & 100 & 00 & 00 \\
\hline 6. Breast tenderness & 10 & 100 & 00 & 00 & 02 & 100 & 00 & 00 \\
\hline 7. Abdominal bloating & 10 & 100 & 00 & 00 & 02 & 100 & 00 & 00 \\
\hline 8. Extreme tiredness & 10 & 100 & 00 & 00 & 02 & 100 & 00 & 00 \\
\hline 9. Constipation & 09 & 90 & 01 & 10 & 02 & 100 & 00 & 00 \\
\hline 10. Mood swing & 10 & 100 & 00 & 00 & 02 & 100 & 00 & 00 \\
\hline
\end{tabular}

Table 14 shows distribution of were vaccinated with Covishield, majority female participants aged 40-49 years who had menstrual issues and those who were 
vaccinated with Covaxin 50\% had no menstrual issues. Chi-Square test or proportion test no possible for both
Covishield and Covaxin in age group 40-49 years as observed frequencies do not match requirements of the test.

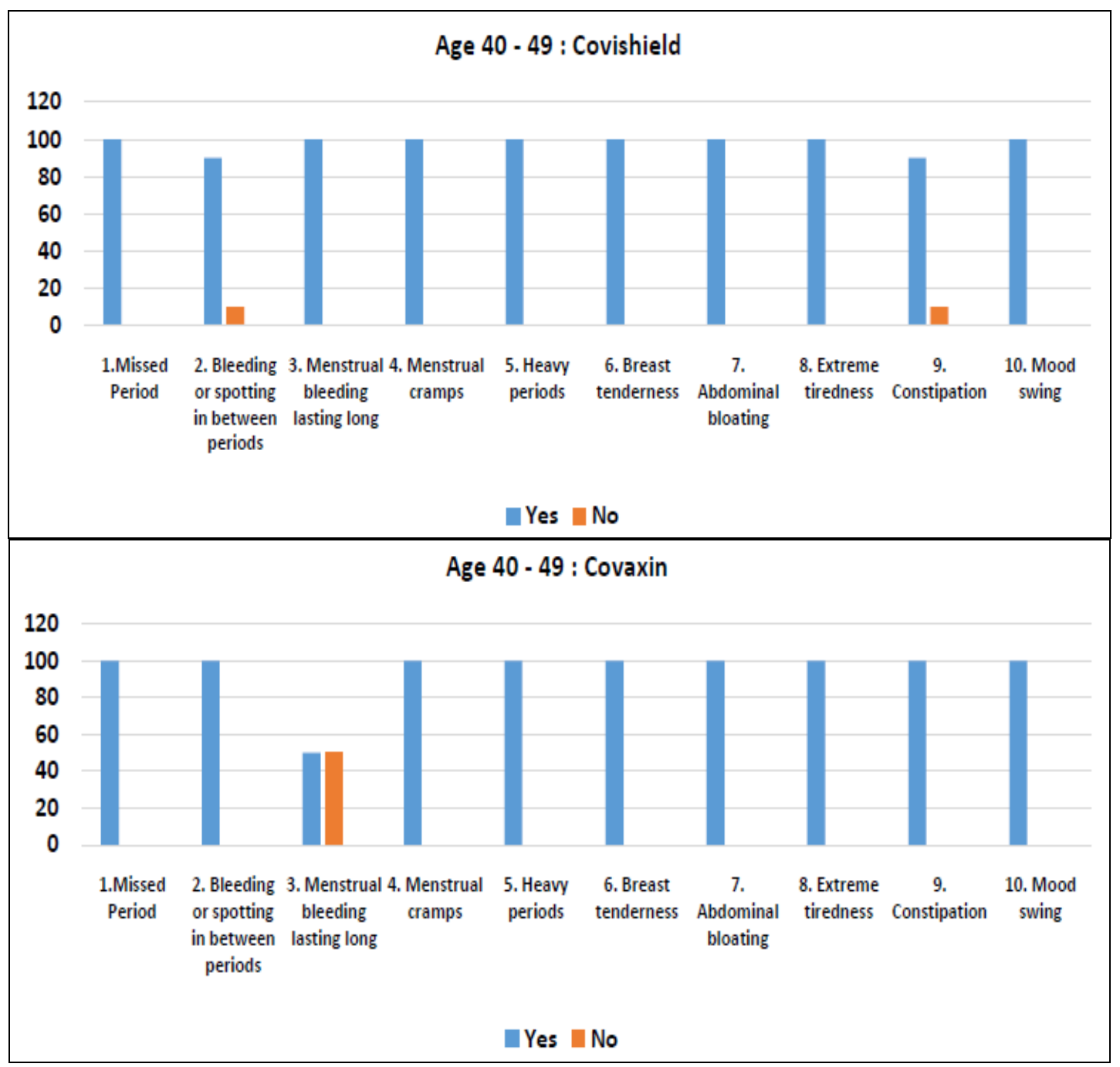

Table 15: Distribution of female participants aged 50 years and above who were vaccinated with Covishield/Covaxin and the menstrual issues.

\begin{tabular}{|l|c|c|c|c|c|c|c|c|}
\hline \multirow{2}{*}{ Menstrual issues } & \multicolumn{4}{c|}{ Covishield (N = 1) } & \multicolumn{4}{c|}{ Covaxin (N= 00) } \\
\cline { 2 - 10 } & Yes & \% & No & \% & Yes & \% & No & $\%$ \\
\hline 1.Missed Period & 01 & 100 & 00 & 00 & 00 & 00 & 00 & 00 \\
\hline 2. Bleeding or spotting in between periods & 01 & 100 & 01 & 10 & 00 & 00 & 00 & 00 \\
\hline 3. Menstrual bleeding lasting long & 01 & 100 & 00 & 00 & 00 & 00 & 00 & 00 \\
\hline 4. Menstrual cramps & 01 & 100 & 00 & 00 & 00 & 00 & 00 & 00 \\
\hline 5. Heavy periods & 01 & 100 & 00 & 00 & 00 & 00 & 00 & 00 \\
\hline 6. Breast tenderness & 01 & 100 & 00 & 00 & 00 & 00 & 00 & 00 \\
\hline 7. Abdominal bloating & 01 & 100 & 00 & 00 & 00 & 00 & 00 & 00 \\
\hline 8. Extreme tiredness & 01 & 100 & 00 & 00 & 00 & 00 & 00 & 00 \\
\hline 9. Constipation & 01 & 100 & 01 & 10 & 00 & 00 & 00 & 00 \\
\hline 10. Mood swing & 01 & 100 & 00 & 00 & 00 & 00 & 00 & 00 \\
\hline
\end{tabular}

Table 15 shows that only one female participant aged 50 years and above was vaccinated with Covishield and she had menstrual issues before vaccination too. Therefore statistical analysis possible in this case. 


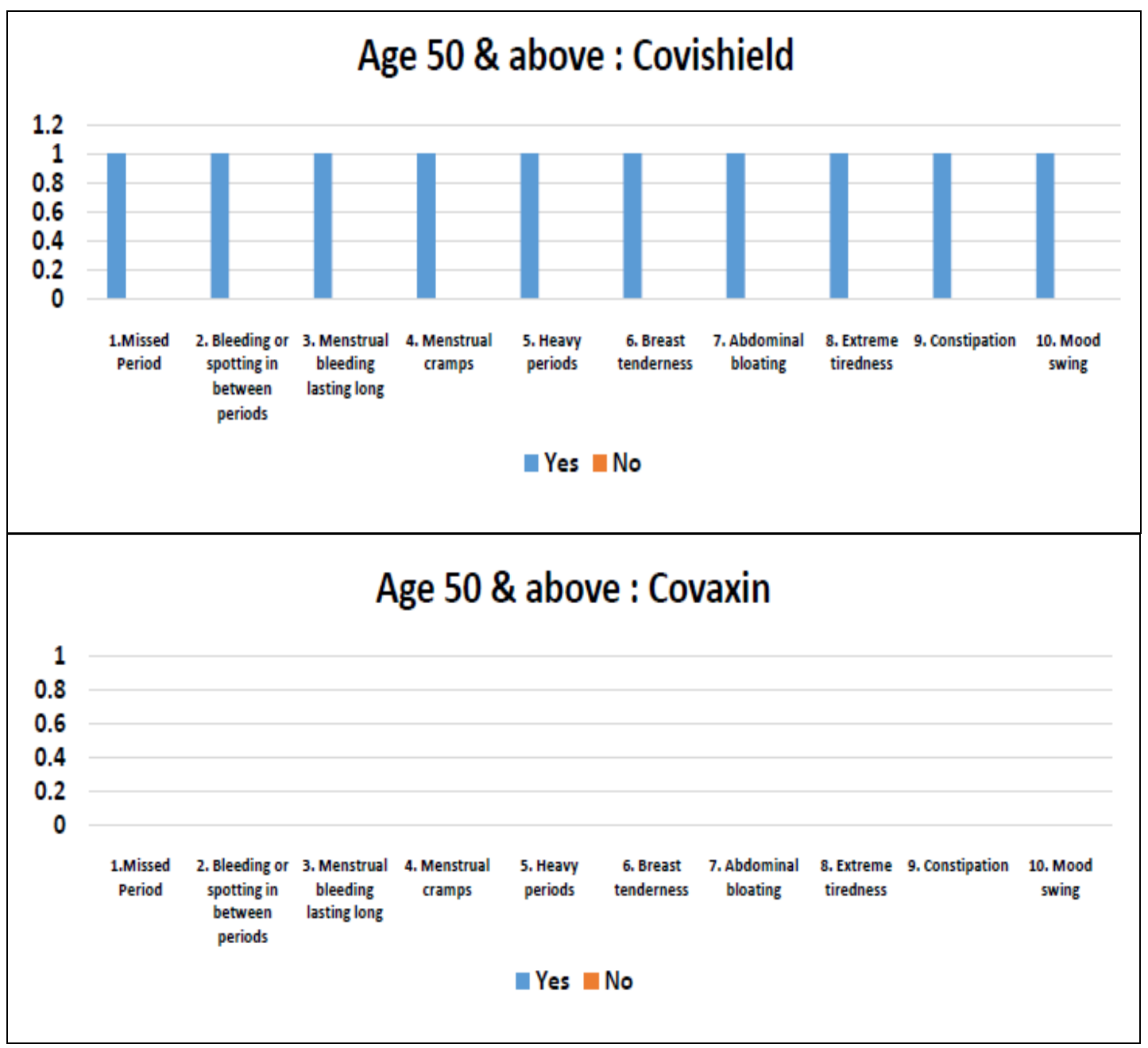

\section{DISCUSSION}

The present study showed that $88 \%$ had taken Covishield and $12 \%$ had taken Covaxin. Majority that is $68 \%$ of the female participants belonged to the age group of 18-26 years, $63 \%$ were Hindus and $65 \%$ belonged to nuclear family. In terms of the educational status $55 \%$ were graduates and $49 \%$ were studying. Majority that is $67 \%$ had their first menstrual period at the age of 13-15 years and 91\% had no menstrual problem before Covid 19 vaccination.

Distribution of 88 female participants according to Covishield vaccine and the menstrual issues revealed that $14 \%$ had missed periods, $10 \%$ had bleeding or spotting in between periods, $13 \%$ had menstrual bleeding lasting long, $58 \%$ had menstrual cramps, $18 \%$ had heavy periods, $24 \%$ had breast tenderness, 39\% had abdominal bloating, $27 \%$ had extreme tiredness, $11 \%$ had constipation and $47 \%$ had mood swings. Distribution of 12 female participants according to Covaxin vaccine and the menstrual issues revealed that $33 \%$ had missed periods, $25 \%$ had bleeding or spotting in between periods, $08 \%$ had menstrual bleeding lasting long, 50\% had menstrual cramps, $17 \%$ had heavy periods, $33 \%$ had breast tenderness, 33\% had abdominal bloating, $67 \%$ had extreme tiredness, $25 \%$ had constipation and 58\% had mood swings.

Distribution of female participants aged $<20$ years who were vaccinated with Covishield/Covaxin revealed that none of the participants in this age group reported any menstrual issues except one person who had extreme tiredness after Covaxin. ChiSquare test or proportion test no possible for both Covishield and Covaxin in age group $<20$ as observed frequencies do not match requirements of the test. 
Distribution of female participants aged 20 -29 years who were vaccinated with Covishield/Covaxin revealed that for Covishield the proportion test for menstrual cramps revealed $\mathrm{Z}=0.426$ (not significant, ' $\mathrm{p}$ '>0.05), abdominal bloating $\mathrm{Z}=7.249$ (significant, 'p' $<0.01$ ) and mood swing $\mathrm{Z}=2.558$ (significant, ' $\mathrm{p}$ '<0.01) For Covaxin Chi square or proportion test not possible in age group 20-29 years as observed frequencies do not match requirements of the test.

Distribution of female participants aged 30-39 years who were vaccinated with Covishield/Covaxin revealed that for Covishield the proportion test for breast tenderness revealed $\mathrm{Z}=0.343$ (not significant, 'p'>0.05). Chi square test \& proportion test for missed bleeding, periods lasting long, and cramps is not possible as the observed frequencies do not match requirements of the test. For Covaxin Chi square or proportion test not possible in age group 30-39 years as observed frequencies do not match requirements of the test.

Distribution of female participants aged 40-49 years who were vaccinated with Covishield, majority had menstrual issues and those who were vaccinated with Covaxin 50\% had no menstrual issues. ChiSquare test or proportion test no possible for both Covishield and Covaxin in age group 40-49 years as observed frequencies do not match requirements of the test.

Only one female participant aged 50 years and above was vaccinated with Covishield and she had menstrual issues before vaccination too. Therefore statistical analysis possible in this case.

\section{CONCLUSION}

Any vaccine has its own effects and side effects and so is the vaccination against Covid-19 too. As the present study had disproportionate sample size, inference could not be possible. Hence it is unclear if Covid-19 vaccination led to menstrual issues. Further studies on these issues with greater sample size could help us to understand the effect of Covid-19 vaccination on menstrual issues.

Acknowledgement: None

Conflict of Interest: None

\section{Source of Funding: None}

\section{Ethical Approval: Approved}

\section{REFERENCES}

1. Darcy Jimenez, "Covid - 19 vaccines and periods:What do we know so far?", Pharmaceutical technology,13 July 2021.

2. Maria Cohut, "Can Covid-19 vaccines affect periods?", Medical New Today, $2^{\text {nd }}$ July 2021.

3. Olga Robinson \& Rachel Schraer, " Covid vaccine: Period changes could be a short term side effect", BBC reality check, $13^{\text {th }}$ May 2021.

4. Time of India. "Coronavirus vaccines: Do Covid 19 vaccines really delay your periods and menstrual cycle? Separating fact from fiction", $28^{\text {th }}$ July 2021.

5. WHO, "Novel Coronavirus -2019".

How to cite this article: Sheela.J. COVID-19 vaccination and menstrual issues - a survey. International Journal of Science \& Healthcare Research. 2021; 6(3): 298-308. DOI: https:// doi.org/10.52403/ijshr.20210752 